\title{
Development of Genetic Linkage Map and Identification of QTLs for Agronomic Traits in Chickpea (Cicer arietinum L.)
}

\author{
Dalpat Lal ${ }^{1,2^{*}}$ and R.L. Ravikumar ${ }^{1}$ \\ ${ }^{1}$ Department of Plant Biotechnology, University of Agricultural Sciences, GKVK, Bengaluru, \\ Karnataka - 65, India \\ ${ }^{2}$ Faculty of Science, Department of Agriculture, Jagannath University, Jaipur, India \\ *Corresponding author
}

\begin{tabular}{|l|}
\hline Ke y w or d s \\
RILs, Linkage \\
group, Genetic map, \\
QTLs, PVE
\end{tabular}

\section{A B S T R A C T}

(Cicer arietinum L.) is one of the important legume rabi season crop in production among the world pulse crops. The aim of the study was to identify quantitative trait loci (QTLs) linked to seed yield and yield related traits in a recombinant inbred lines (RIL) derived from the cross of Fusarium wilt susceptible (JG62) and resistant (WR315). The population consisting of 125 RILs was grown under field condition over two seasons. The population were genotyped with sixty polymorphic markers and phenotyped for agronomic and yield related traits. A genetic map composed of two linkage groups (LGs) covering $768.92 \mathrm{cM}$ was constructed. QTL analysis was performed by composite interval mapping (CIM) using ICIM QTL Mapping version 4.00 software. Total five QTLs were identified for productivity related traits with a LOD score from 3.18 to 11.42. One QTL (qPods 13-2-1) for number of pods per plant explaining a phenotypic variance (PVE) of $11.05 \%$ were observed in 2013, four QTLs were identified in 2014, two QTLs (qFlowering 14-1-1 and qFlowering 14-1-2) for days taken to 50\% flowering explaining a PVE of $28.07 \%$ and $40.10 \%$ respectively and two QTLs ( $q T W 14-1-1$ and $q T W 14-2-1$ ) for 100 seed weight explaining a PVE of $11.56 \%$ and $19.29 \%$ respectively. The identified markers could be used in marker assisted selection (MAS) in chickpea breeding programmes after validation.

\section{Introduction}

Chickpea (Cicer arietinum L.), is an annual self-pollinated and diploid $(2 \mathrm{n}=16)$ most important grain legume rabi season crop with genome size of $\sim 738 \mathrm{Mb}$ (Karami et al., 2015). Globally, chickpea is cultivated on 11.55 million hectares with an annual production of 10.46 million tons and average productivity of $905 \mathrm{~kg} / \mathrm{ha}$. India is the largest producer of chickpea, accounts for about $70 \%$ of the world chickpea production followed by Australia (6.21\%), Pakistan (5.73\%), Turkey (3.86 \%), Myanmar (3.74\%), Iran (2.25\%), USA (0.84 \%), Canada (0.78 \%), and Mexico (0.62\%) (FAO, 2015).

Chickpea was first cultivated in an area of south-eastern Turkey and adjoining Syria but is now cultivated throughout the semi-arid regions of the world (Knights et al., 2007). In cultivated chickpea, there are two distinct 
types - desi and kabuli, mainly based on their seed colour and shape. Desi chickpea is usually small seeded, angular in shape, with seed colours ranging from white to black, and seed surface is smooth or rough. The aerial plant parts usually have anthocyanin pigmentation and the plants usually have pink or purple flowers with semi-erect or semispreading growth habit. They are mostly distributed in south Asia, Ethiopia, Tanzania and to some extent in Mexico, and Iran. They are adapted to winter sowing in the sub-tropics and hilly areas of tropics. The kabuli, on the other hand, are usually large seeded with Owl's head shape and white or light pinkish seed coat. The plants are green, lack anthocyanin pigmentation and the flowers are white with semi-spreading growth habit. Kabuli chickpea is distributed mainly in the Middle East and Mediterranean region, Spain, Chile and Mexico and are adapted to spring sowing at higher altitudes. In recent years these are also grown in the United States of America (Karami et al., 2015).

Yield is a complex trait, resulting from complete development of the plant. Therefore, yield usually shows low heritability. In chickpea, correlations have been reported between seed yield and its components (seeds per pod, pods per plant, seeds per plant, yield per plant, seed size, etc.) (Maynez et al., 1993; Karami, 2011; Talebi and Karami, 2011). However, results obtained do not tend to corroborate each other possibly because of the differences in the material used (collections or segregate populations) or environments (different locations or years). Number of days to flowering is an important trait for crop adaptation and productivity, especially under dryland farming systems that experience terminal drought conditions. Therefore, the ability to manipulate flowering time is an essential component of chickpea improvement (Kumar and Abbo, 2001). The low yield of chickpea is mostly due to its susceptibility to various biotic and abiotic stresses. Molecular marker based linkage maps have been useful in identifying and localizing important genes controlling both qualitatively and quantitatively inherited traits in a wide range of species (Tanksley et al., 1989). Marker assisted selection (MAS) of agronomical desirable traits such as yield, quality, biotic and abiotic stress resistance, etc. requires an intra-specific linkage map saturated with codominant and single-locus PCR based markers like SSRs. SSRs also enable transfer of linkage information among maps developed from different populations and can be used as anchors to combine the maps to develop a highly saturated consensus map.

MAS provides an efficient means of selecting specific alleles, and also for selecting against undesirable traits introduced as a result of a wide cross. The identification of appropriate markers requires the definition of linkage relationships, and some of the requisite mapping populations in chickpea have been developed from crosses between $C$. arietinum and $C$. reticulatum (Simon and Muehlbauer, 1997; Winter et al., 2000; Tekeoglu et al., 2002; Abbo et al., 2005).

Several attempts have been made to map quantitative trait loci (QTLs) and their flanking regions for different agronomic traits. Cho et al., (2002) developed an intraspecific genetic linkage map and determined map positions of genes that confer double podding(s) and seed traits using a population of $76 \mathrm{~F}_{10}$ derived RILs from the cross ICCV 2 (large seeds and single pods) x JG 62 (small seeds and double podded). Further, several molecular studies has been reported for agronomic traits (Abbo et al., 2005; Lichtenzveig et al., 2006; Cobos et al., 2009; Hossain et al., 2010; Gowda et al., 2011; Jamalabadi et al., 2013; Saxena et al., 2014; Karami et al., 2015; Das et al., 2015). These maps have allowed for a range of genes and 
QTL to be linked to markers because these maps are based on different mapping population, traits, location and years (Winter et al., 2000; Abbo et al., 2005; Cobos et al., 2006). However, no single population would segregate for all the economic traits of interest, genes for those traits need to be mapped on linkage maps developed from different segregating populations. As the map becomes saturated with more markers, complex traits could be dissected and utilized efficiently in breeding programs. Therefore, the objective of the present study was to construction of a genetic linkage map and molecular marker analysis to identify QTLs that control seed yield and yield related traits using a recombinant inbred lines (RILs) developed from intraspecific cross between JG62 and WR 315. The identified QTLs/ linked markers can be utilized for MAS in improving the yield of chickpea.

\section{Materials and Methods}

\section{Plant material}

A set of 125 intraspecific $\mathrm{F}_{10: 11}$ RILs of a cross between JG 62 (susceptible) and WR 315 (resistant) segregating for Fusarium wilt (FW) resistance were selected. The genotype JG 62, is an Indian origin desi type, early flowering, double podded whereas, WR 315 is a desi landrace from central India and resistant to race $1 \mathrm{~A}$, race 2 , race 3 , race 4 and race 5 of FW (Mayer et al., 1997).

The mapping population (RILs) was developed by single seed descent method and evaluated for six morphological traits: days to $50 \%$ flowering, plant height at maturity $(\mathrm{cm})$, number of branches per plant, number of pods per plant, seed yield per plant and test weight under field conditions over two rabi seasons 2013 and 2014 at University of Agricultural Sciences, GKVK, Bengaluru. The first season trial was laid out in Augmented design and second season Randomized Complete Block design with two replications. However, in both the seasons each line was grown in a row of 2.5 m length with $30 \mathrm{~cm}$ spacing between rows and $10 \mathrm{~cm}$ with in row. All the recommended agronomic practices with regular irrigations were followed for better crop growth.

\section{Genomic DNA extraction and marker analysis}

The genomic DNA was extracted from vegetative buds and young leaves of RILs and parental lines by CTAB method with slight modifications (Doyle and Doyle, 1990). DNA quantity and quality were assessed with a spectrophotometer. A set of novel microsatellite markers developed at National Institute of Plant Genome Research (NIPGR), New Delhi, along with earlier reported SSR markers were used to survey parental polymorphism (Jhanwar et al., 2012). The genic SSRs were developed from transcriptome sequence of various tissues of chickpea variety ICC4958, using next generation sequencing platforms (Garg et al., 2011). The genomic markers were based on the draft genome sequence of desi chickpea (Jain et al., 2013). The parental lines JG62 and WR315 were tested for polymorphisim with SSR markers in $10 \mu \mathrm{L}$ reactions using thermal cycler (Master cycler gradient, Eppendorf, Hamburg, Germany). The PCR products from each tube along with5 $\mu \mathrm{L}$ of loading dye were separated electrophoretic ally using 3.0\% agarose gels containing $0.05 \mu \mathrm{g} / \mathrm{mL}$ ethidium bromide and $8 \%$ PAGE with silver staining. The amplification products were examined under UV light and photographed using Alpha digidoc 1000 system (Alpha Innotech Corporation, USA) gel documentation system. The polymorphic markers were used to genotype all the RILs and the data was recorded and subsequently used for mapping studies. 
Linkage map constriction and QTL analysis

The segregation of markers was tested for goodness of fit to the expected ratio of $1: 1$ using chi-square $(\chi 2)$ test $(P<0.05)$. Single marker analysis and linkage mapping was performed using ICIM QTL Mapping version 4.00 software (http://www.isbreeding.net). A minimum LOD of 3.0 and maximum recombination fraction of 0.3 were set as threshold value for linkage groups (LGs) determination. 'Ripple' command was used after adding each marker locus to confirm marker order. Recombination frequencies were converted into genetic distances in centimorgans (cM) using Kosambi mapping function (Kosambi, 1944). Furthermore, the genotypic data combined with phenotypic data obtained from two seasons of field data on 125 RILs, were analysed for identification of the QTLs using ICIM QTL Mapping version 4.00. The QTL analysis was performed by composite interval mapping (CIM) (Jansen and Stam, 1994; Zeng, 1994). A minimum LOD score of 3.0 was used for declaring the presence of a putative QTL.

\section{Results and Discussion}

\section{Linkage map}

A set of 400 SSRs markers were screened for polymorphism on the parents (JG 62 and WR 315) of RILs and a total of 60 SSRs primers were consistently polymorphic between the parents. All the polymorphic primers were used for genotyping and the entire mapping population consisting of 125 RILs was screened.

The segregation of individual markers for the expected monogenic 1:1 ratio in the RILs was tested using Chi square test. Out of 60 SSR markers screened $9 \quad(15 \%)$ showed segregation distortion $(\mathrm{P}<0.05)$ from the expected Mendelian ratio (1:1) and five markers were skewed towards female parent and four marker towards the male parent. Of the 60 markers used for mapping, 56 markers were mapped in two linkage groups (LGs) spanning a total length of $768.92 \mathrm{cM}$ with an average marker density of $13.73 \mathrm{cM}$ (Fig. 1). The length of the linkage group ranged from smallest $35.93 \mathrm{cM}$ (LG 2) to largest 732.99 cM (LG 1). The number of markers mapped per linkage group varied from 3 (LG 2) to 53 markers (LG 1). The highest marker density was observed in LG 2 with an average marker density of $11.98 \mathrm{cM}$ and the least marker density of $13.83 \mathrm{cM}$ was observed in LG 1 .

The single marker analysis was carried out to identify the putative markers associated with agronomic and yield traits at different seasons based on phenotypic variance (PVE \%). A total of five markers were associated with seed yield and yield related traits with a range of phenotypic variance from $11.05 \%$ to $17.86 \%$ (Table 1). The marker GSSR 87 (17.86\%) was strongly associated with test weight in rabi 2014. The markers GSSR 18 (16.69\%), TA $117(16.88 \%)$ and TAA $55(14.83 \%)$ also showed significant association with test weight in 2014 season. Similarly, GSSR 18 $(11.05 \%)$ and UASBC $4(11.52 \%)$ showed linkage to numbers of pod per plant in 2013 and days taken to 50\% flowering in 2014 respectively.

\section{QTL analysis}

\section{QTLs analysis for rabi 2013}

Only one QTL (qPods 13-2-1) for number of pods per plant was identified in 2013. The QTL was located on LG 2 with a LOD score of 3.18 and flanked by GSSR 18 and NCPGR 48 markers (Table 2). The QTL explained phenotypic variation of $11.05 \%$ for the trait and had positive additive effect (6.76) with male parent contributing for favourable allele. 


\section{QTLs analysis for rabi 2014}

A total of four QTLs were identified in 2014 (Table 2), two QTLs (qFlowering 14-1-1 and qFlowering 14-1-2) for days taken to $50 \%$ flowering and two QTLs ( $q T W$ 14-1-1 and $q T W$ 14-2-1) for 100 seed weight.

Two QTLs (NCPGR 45 - H4G11 and UASBC 4 - TA 72) for days to $50 \%$ flowering were located at $150.0 \mathrm{cM}$ and $205.0 \mathrm{cM}$ on LG 1 and both the QTLs were detected with a LOD score of 7.26 and 11.42 respectively. The first (NCPGR 45- H4G11) and second (UASBC 4 TA 72) QTLs explained a phenotypic variance of $28.07 \%$ and $40.10 \%$ for the trait.

The additive effect of QTLs (NCPGR 45 H4G11 and UASBC 4- TA 72) had negative (1.18) and positive (1.41) with a favourable alleles were contribution from female and male parent respectively, for days to $50 \%$ flowering.

Two QTLs (TA 117-GSSR 87 and GSSR 18NCPGR 48) for 100 seed weight were located at $686.0 \mathrm{cM}$ and $6.0 \mathrm{cM}$ on LG 1 and LG 2 and the QTLs were detected with a LOD score of 3.89 and 3.77 respectively. The QTLs (TA 117 - GSSR 87; GSSR 18 - NCPGR 48) explained a phenotypic variance of 11.56 and $19.29 \%$ respectively and favourable allele was from female parent with an additive effect of -0.47 and -0.69 respectively.

In the present investigation we are reporting new genomic markers (GSSR 18 and GSSR 87) linked to number of pod per plant and test weight respectively and genic marker (UASBC 4) linked for days to $50 \%$ flowering.

Furthermore, it is interesting to note that two QTLs influencing number of pods per plant and test weight (qPods 13-2-1; qTW 14-2-1) were located in the same genomic region of LG2. These QTLs identified in the present study were different and not reported earlier. Therefore, these QTLs are to be further confirmed before using them in breeding programmes.

Chickpea is a major food legume and an important source of protein in many countries in Asia. Its production in these countries is still low (0.78 t/ha) and limited by biotic and abiotic stress factors (Upadhyaya et al., 2001). Seed yield is a complex character controlled by several genetic and environmental factors and depends on the interaction of many other characters.

We have identified QTLs for three agronomic and yield traits in chickpea using a set of RILs as a mapping populations. Total 400 SSRs markers were screened and of 60 markers were found polymorphic between the parents JG 62 and WR 315. The Chi square results observed that $9(15 \%)$ markers showed segregation distortion $(\mathrm{P}<0.05)$ from the expected Mendelian ratio (1:1) and five markers were skewed towards female parent and four marker towards the male parent. The observed segregation distortion in present study is most favour of the maternal alleles (JG 62) as reported from Flandez-Galvez et al., (2003).

This might be due to accumulation of distorted alleles in the population with progressive cycles of selfing undergone in the development of the RILs (Flandez-Galvez et al., 2003). Segregation distortion affects the estimation of map distances and the order of markers when many distorted markers are used for linkage map construction and hence affects the QTL analysis. Though, Winter et al., (2000) observed different amounts of segregation distortion for different classes of markers, he reported that segregation distortion is less related to the class of affected markers than to the genomic region where they resided. 
Fig.1 Linkage map showing QTLs identified for agronomic traits in JG62 x WR315 mapping population of chickpea

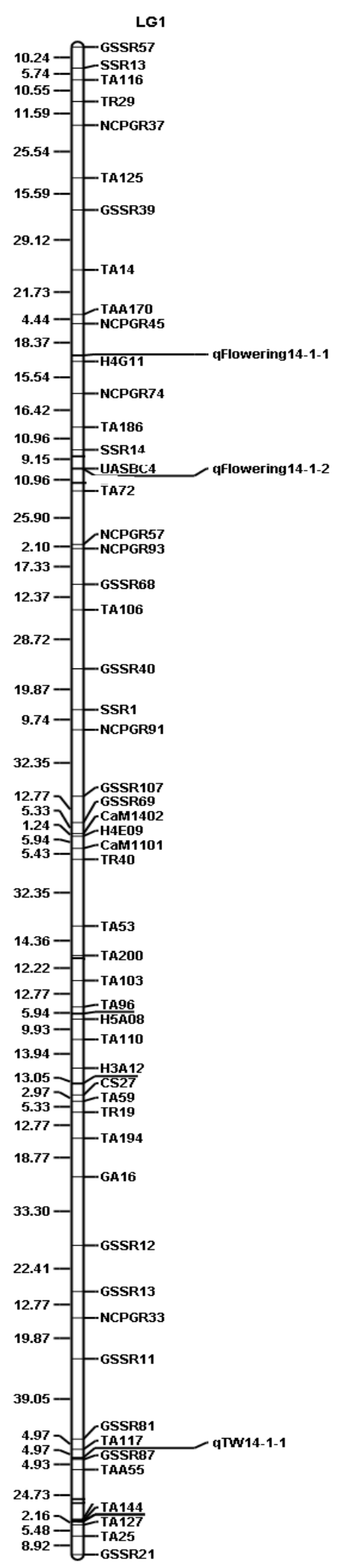


Table.1 Single marker analysis for seed yield and yield traits

\begin{tabular}{|c|c|c|c|c|c|}
\hline Trait & $\begin{array}{c}\text { Linkage } \\
\text { Group }\end{array}$ & Marker & $\begin{array}{c}\text { Max } \\
\text { LOD }\end{array}$ & PVE (\%) & $\begin{array}{c}\text { Additive } \\
\text { effect }\end{array}$ \\
\hline Pods (2013) & 2 & GSSR 18 & 3.18 & 11.05 & 6.76 \\
\hline Flowering (2014) & 1 & UASBC 4 & 3.33 & 11.52 & 0.75 \\
\hline Test weight (2014) & 1 & TA 117 & 5.02 & 16.88 & -0.57 \\
\hline Test weight (2014) & 1 & GSSR 87 & 5.34 & 17.86 & -0.59 \\
\hline Test weight (2014) & 1 & TAA 55 & 4.35 & 14.83 & -0.54 \\
\hline Test weight (2014) & 2 & GSSR 18 & 4.96 & 16.69 & -0.61 \\
\hline
\end{tabular}

$\mathrm{PVE}=$ Phenotypic variation explained by the marker

Table.2 QTLs detected for seed yield and yield related traits in RILs

\begin{tabular}{|c|c|c|c|c|c|c|c|}
\hline Seasons & Trait & $\begin{array}{l}\text { Linkage } \\
\text { group }\end{array}$ & $\begin{array}{l}\text { Flanking } \\
\text { marker }\end{array}$ & $\begin{array}{l}\text { QTL } \\
\text { Position } \\
\text { (cM) }\end{array}$ & $\begin{array}{c}\text { Max } \\
\text { LOD } \\
\text { Score }\end{array}$ & $\begin{array}{l}\mathbf{R}^{2} \\
(\%)\end{array}$ & $\begin{array}{c}\text { Additive } \\
\text { effect }\end{array}$ \\
\hline $\begin{array}{l}\text { Rabi } \\
2013\end{array}$ & $\begin{array}{l}\text { Number of } \\
\text { pods per plant }\end{array}$ & 2 & $\begin{array}{l}\text { GSSR 18- } \\
\text { NCPGR } 48\end{array}$ & 0.0 & 3.18 & 11.05 & 6.76 \\
\hline \multirow[t]{4}{*}{$\begin{array}{l}\text { Rabi } \\
2014\end{array}$} & $\begin{array}{l}\text { Days for } 50 \% \\
\text { flowering }\end{array}$ & 1 & $\begin{array}{l}\text { NCPGR 45- } \\
\text { H4G11 }\end{array}$ & 150.0 & 7.26 & 28.07 & -1.18 \\
\hline & $\begin{array}{l}\text { Days for } 50 \% \\
\text { flowering }\end{array}$ & 1 & $\begin{array}{c}\text { UASBC 4- } \\
\text { TA } 72\end{array}$ & 205.0 & 11.42 & 40.10 & 1.41 \\
\hline & Test weight & 1 & $\begin{array}{l}\text { TA } 117- \\
\text { GSSR } 87\end{array}$ & 686.0 & 3.89 & 11.56 & -0.47 \\
\hline & Test weight & 2 & $\begin{array}{l}\text { GSSR 18- } \\
\text { NCPGR } 48\end{array}$ & 6.0 & 3.77 & 19.29 & -0.69 \\
\hline
\end{tabular}

Only two out of eight possible linkage groups were obtained in the present study and map obtained is also less dense compared to earlier workers [Winter et al., 2000 (2077.9 cM, 16 LG), Cobos et al., 2005 (330.03 cM, 11 LG), Radhika et al., 2007 (509.3 cM, 7 LG and 623.9 cM 7 LG) and Nayak et al., 2010 (2602 $\mathrm{cM}, 8$ LG)]. It may be due to use of less number of markers for mapping and relaxed recombination fraction 0.3 . The different genotypes of the same species usually show different rates of recombination, and this difference may sometimes be more than 20 $\%$. For this reason, genetic distances between given pairs of markers estimated from different mapping populations of the same species may not necessarily be identical.
The mapping population is vital to have sufficient diversity to allow mapping of several traits using the same population. Most of the mapping studies with molecular markers have used either $F_{2}$ populations or backcrosses. But RILs developed by single seed descent method from $\mathrm{F}_{2}$ population have several advantages over other populations for genetic mapping. RILs are homozygous and they can be evaluated in different environments, which is useful in analysis of quantitative traits and it also helps in the accurate assessment of the genetic component of variance. RILs developed by selfing, there is a 2 to 4 fold increase in the recombination frequency between two linked markers. In the present study RILs were evaluated for six 
yield and yield attributing traits viz., days to 50 per cent flowering, plant height at maturity, number of branches per plant, number of pods per plant, 100 seed weight and seed yield per plant over two seasons.

In present study we mapped yield related traits such as days for $50 \%$ flowering, number of pods per plant and 100-seed weight. However, days to flowering is considered an important adaptive trait because crops have to grow in different temperature and photoperiod regions (Khanna-Chopra and Sinha, 1987). The Mediterranean chickpea seems to have evolved toward long-day sensitivity, but on the Indian subcontinent and in East Africa, the chickpea has evolved toward short photoperiods (Kumar and Abbo, 2001). Furthermore, the inheritance of flowering time in chickpea is controlled by two QTLs with epistatic interaction (Hegde, 2010). Oligogenic inheritance of flowering time has been reported by Gumber and Sarvjeet (1996) and Anbessa et al., (2006), who suggested that two genes controlled flowering time. Later, Kumar and van Rheenen (2000) suggested the presence of a major gene (Efl1/efl-1) and minor polygenes for this trait and these differences among reports are probably due to differences in the parents used, but environmental influences such as day length and temperature may also have differed between studies. Cho et al., (2002) also reported a QTL for days to flowering in LG3; they used a RIL from a cross between the ICCV2 and JG62. Aryamanesh et al., (2010) mapped two QTLs for days to flowering on LG3, and Cobos et al., (2007) reported one on LG4. Although two QTLs for days to flowering in our study were found on LG1, their location and markers on the linkage group was different from those of Cho et al., (2002); Aryamanesh et al., (2010) and Jamalabadi et al., (2013), suggesting the presence of different genes for the control of flowering time. It may also reflect differences in population, markers, and linkage map analysis. On the other hand, Lichtenzveig et al., (2006) reported two QTLs on LG2 and LG8 for days to flowering, which were also not detected in our population. Based on these findings, it is suggests that several unknown factors affect time to flowering in chickpea.

Several earlier published map linked markers were on LG1 of the JV (JG $60 \mathrm{x}$ Vijay) map and LG1a of the VI (Vijay x ICC4958) map, which correspond to the LGs 1, 4 and 5 of the chickpea reference map (Winter et al., 2000), contained QTLs for many traits, viz. plant height, plant spread, number of branches per plant, number of pods per plant, yield, seed weight and days to maturity (Gowda et al., 2011); seed number per plant, 100- seed weight, days to $50 \%$ flowering (Cho et al., 2002); seed weight and lutein concentration (Abbo et al., 2005) and seed size, yield and days to 50\% flowering (Cobos et al., 2009).

In earlier study TA 117 is one of the flanking markers reported for various agronomic and yield traits viz. plant spread, number of branches per plant and days to maturity (Gowda et al., 2011). Recently, Jingade, (2014) in an intraspecific mapping population identified QTLs (TA186 - GSSR 50 and GSSR 50 - TA 72) for seed yield per plant, QTL (TA 72 - GSSR 41) for plant height at maturity and two QTLs (GSSR 50 - TA 72 and TA 72 - GSSR 41) for 100 seed weight. We are also identified QTLs for seed weight on LG 1 and LG 2 and these results were agreed to Abbo et al., 2005; Cobos et al., 2007 but contrast to LG9 (Cho et al., 2002). Upadhyaya et al., (2006) reported that seed weight was controlled by at least two major genes, and these two QTLs also identified in the present study might correspond to these genes. On chickpea published map, this genomic region was poorly saturated, so to obtain more robust markers in this interesting region, SSR markers will be more informative 
and effective. However, most of the markers in present study located on LG 1 but these markers were located on LG 2 of earlier consensus map (Millan et al., 2010). However, the map distances and marker orders of the common SSR markers differed, possibly due to the intra-specific nature of our mapping populations.

In conclusion we have added 14 new markers to chickpea map and new QTLs have been identified for number of pods per plant, days to $50 \%$ flowering and test weight. Henceforth, these trait-regulating QTLs, once successfully validate in diverse genetic backgrounds, can be utilized for mapping and tagging of the genes or QTLs governing traits such as yield and yield-related agronomic characters, and quality in chickpea breeding programs.

\section{Acknowledgment}

Dalpat Lal acknowledges to Department of Biotechnology, Government of India for DBT-JRF/SRF fellowship and Department of Plant Biotechnology, UAS, GKVK, Bengaluru.

\section{References}

Abbo, S., Molina, C., Jungmann, R., Grusak, M., Berkovitch, Z., Reifen, R., Kahl, G., Winter, P. and Reifen, R. 2005. Quantitative trait loci governing carotenoid concentration and weight in seeds of chickpea (Cicer arietinum L.). Theor. Appl. Genet., 111(2): 185-202.

Anbessa, Y., T. Warkentin, A. Vandenberg, Ball, R. 2006. Inheritance of time to flowering in chickpea in a short season temperate environment. J. Hered., 97: $55-61$.

Aryamanesh, N., M.N. Nelson, G. Yan, H.J. Clarke, Siddique, K.H.M. 2010. Mapping a major gene for growth habit and QTLs for ascochyta blight resistance and flowering time in a population between chickpea and Cicer reticulatum. Euphytica, 173:307-319.

Bajaj, D., Upadhyaya, H. D., Khan, Y., Das, S., Badoni, S., Shree, T., Kumar, V., Tripathi, S., Gowda, L. L., Singh, S., Sharma, S., Tyagi, A. K., Chattopdhyay, D. and Parida, S. K. 2015. A combinatorial approach of comprehensive QTL-based comparative genome mapping and transcript profiling identified a seed weightregulating candidate gene in chickpea. Sci. Rep., 5: $9264 . \quad$ DOI: 10.1038/srep09264.

Cho, S., Kumar, J., Shultz, J. L., Anupama, K., Tefera, F. and Muehlbauer, F. J. 2002. Mapping genes for double podding and other morphological traits in chickpea. Euphytica, 128(2): 285-292.

Cobos, M. J., Rubio, J., Fernandez-Romero, M. D., Garza, R., Moreno, M. T., Millan, T., Gil, J. 2007. Genetic analysis of seed size, yield and days to flowering in a chickpea RIL population derived from a Kabuli X Desi cross. Ann ApplBio., 151: 33-42.

Cobos, M. J., Rubio, J., Strange, R. N., Moreno, M. T., Gil, J. and Millan, T. 2006. A new QTL for Ascochyta blight resistance in an RIL population derived from an interspecific cross in chickpea. Euphytica, 149(1-2): 105-111.

Cobos, M., Fernández, M., Rubio, J., Kharrat, M., Moreno, M., Gil, J. and Millan, T. 2005. A linkage map of chickpea (Cicer arietinum L.) based on populations from Kabuli $\times$ Desi crosses: location of genes for resistance to Fusarium wilt race 0 . Theor. Appl. Genet., 110(7): 1347-1353.

Cobos, M., Winter, P., Kharrat, M., Cubero, J., Gil, J., Millan, T. and Rubio, J. 2009. Genetic analysis of agronomic traits in a wide cross of chickpea. Field Crops Res., 111(1): 130-145. 
Das, S., Upadhyaya, H. D., Bajaj, D., Kujur, A., Badoni, S., Laxmi, Kumar, V., Tripathi, S., Gowda, C. L., Sharma, S., Singh, S., Tayagi, A. K., and Parida, S. K. 2015. Deploying QTL-seq for rapid delineation of a $\mathrm{N}$ potential candidate gene underlying major trait-associated QTL in chickpea. DNA Res., 1-11: doi:10.1093/dnares/dsv004.

Doyle, J. J. and Doyle, J. L. 1990. Isolation of plant DNA from fresh tissue. Focus., 12(1): 13-15.

FAO. 2015. FAOSTATS. Food and Agriculture Organization of the United Nations, Rome, Italy. http://faostat.fao.org.

Flandez-Galvez, H., Ades, P., Ford, R., Pang, E. and Taylor, P. 2003. QTL analysis for ascochyta blight resistance in an intraspecific population of chickpea (Cicer arietinum L.). Theor. Appl. Genet., 107(7): 1257-1264.

Garg, R., Patel, R.K., Tyagi, A.K. and Jain, M. 2011. De novo assembly of chickpea transcriptome using short reads for gene discovery and marker identification. DNA res., 18(1): 53-63.

Gowda, S. J., M Radhika, P., Mhase, L. B., Jamadagni, B. M., Gupta, V. S. and Kadoo, N. Y. 2011. Mapping of QTLs governing agronomic and yield traits in chickpea. J. Appl. Genet., 52: 9-21.

Gumber, R. K. and Sarvjeet, S. 1996. Genetics of flowering time in chickpea: a preliminary report. Crop Imp., 23: 295-296.

Hegde, V.S. 2010. Genetics of flowering time in chickpea in a semi-arid environment. PlBreed., 129: 683-687.

Hossain, S., Ford, R., Mcneil, D., Pittock, C. and Panozzo, J. 2010. Inheritance of seed size in chickpea (Cicer arietinum L.) and identification of QTL based on 100 -seed weight and seed size index. Aus. J. Crop Sci., 4 (2): 150-167.
Jain, M., Misra, G., Patel, R. K., Priya, P., Jhanwar, S., Khan, A. W., Shah, N., Singh, V. K., Garg, R. and Jeena, G. 2013. A draft genome sequence of the pulse crop chickpea (Cicer arietinum L.). The Plant Journal, 74(5): 715-723.

Jamalabadi, J. G., Saidi, A., Karami, E., Kharkesh, M., Talebi, R., 2013. Molecular mapping and characterization of genes governing time to flowering, seed weight and plant height in an intraspecific genetic linkage map of chickpea (Cicer arietinum). Biochem. Gene., 51(5-6): 387-397.

Jansen, R. C. and Stam, P. 1994. High resolution of quantitative traits into multiple loci via interval mapping. Genet., 136: 1445-1447.

Jhanwar, S., Priya, P., Garg, R., Parida, S. K., Tyagi, A. K., Jain, M. 2012. Transcriptome sequencing of wild chickpea as a rich resource for marker development. Plant Biotechnol. J., 10: 690-702.

Jingade, P., 2014, Development of molecular map and Identification of closely linked DNA Markers for fusarium wilt resistance in chickpea (Cicer arietinum L.). Ph. D. Thesis, University of Agricultural Sciences, Bangalore.

Karami E., R. Talebi, M. Kharkesh, and Saidi, A. 2015. A linkage map of chickpea (Cicer arietinum L.) based on population from ILC3279×ILC588 crosses: location of genes for time to flowering, seed size and plant height. Genetika, Vol 47, No. 1, 253-263.

Karami, E. 2011. Genetic analysis of some agronomic characters in chickpea ( $\mathrm{Cicer}$ aretinum L.). Afr J. Agri. Res., 6:13491358.

Khanna-Chopra, R. and Sinha, S. K. 1987. Physiological aspect of growth and yield. In The Chickpea, pp: 163-190. SAXENA, M.C., K.B.SINGH (Eds). 
WALLINGFORD, UK: $\quad$ CAB International.

Knights, E.J., Acikgoz, N., Warkentin, T., Bejiga, G., Yadav, S.S. and Sandu, J.S. 2007. Area, production and distribution. In: Yadav SS, Redden R, Chen W, Sharma B, editors. Chickpea Breeding and Management, pp.167-178, CAB International.

Kosambi, D. D. 1944. The estimation of map distances from recombination values. Ann. Eugen., 12:172-175.

Kumar, J. and Abbo, S. 2001. Genetics of flowering time in chickpea and its bearing on productivity in the semi-arid environments. Adv. Agron., 72: 107138.

Kumar, J. and Rheenen, H. A. 2000. A major gene for time of flowering in chickpea. J. Hered., 91: 67-68.

Lichtenzveig, J., Bonfil, D. and Zhang, H. 2006. Mapping quantitative trait loci in chickpea associated with time to flowering and resistance to Didymellarabiei the causal agent of Ascochytablight. Theor. Appl. Genet., 113: 1357-1369.

Mayer, M., Tullu, A., Simon, C., Kumar, J., Kaiser, W., Kraft, J. and Muehlbauer, F. 1997. Development of a DNA marker for Fusarium wilt resistance in chickpea. Crop Sci., 37(5): 1625-1637.

Maynez, M., M.T. Moreno, J. Gil, 1993. Desi/kabuliintrogression for yield improvement in chickpea (Cicer arietinum L.). J. Genet. Breed., 47: 6164.

Millan, T., Winter, P., Jungling, R., Gil, J., Rubio, J., Cho, S., Cobos, M., Iruela, M., Rajesh, P. and Tekeoglu, M., 2010. A consensus genetic map of chickpea (Cicer arietinum L.) based on 10 mapping populations. Euphytica, 175(2): 175-185.

Nayak, S. N., Zhu, H., Varghese, N., Datta, S., Choi, H.-K., Horres, R., Jungling,
R., Singh, J., Kishor, P. K. and Sivaramakrishnan, S. 2010. Integration of novel SSR and gene-based SNP marker loci in the chickpea genetic map and establishment of new anchor points with Medicago truncatula genome. Theor. Appl. Genet., 120(7): 1415-1428.

Radhika, P., Gowda, S., Kadoo, N., Mhase, L., Jamadagni, B., Sainani, M., Chandra, S., Gupta, V. 2007. Development of an integrated intraspecific map of chickpea (Cicer arietinum L.) using two recombinant inbred line populations. Theor App Genet., 115: 209-216

Rajesh, P.N., Tekeoglu, M., Gupta, V.S., Ranjekar, P.K. and Muehlbauer, F.J. 2002. Molecular mapping and characterization of an RGA locus RGA Ptokin1-2171 in chickpea. Euphytica, 128(3): 427-433.

Saxena, M.S., Bajaj, D., Das, S., Kujur, A., Kumar, V., Singh, M., Bansal, K. C., Tyagi, A. K., and Parida, K. S. 2014. An integrated genomic approach for rapid delineation of candidate genes regulating agromorphological traits in chickpea. DNA Res., 21: 695-710.

Sharma, K. D., Chen, W. and Muehlbauer, F. J. 2005. Genetics of chickpea resistance to five races of Fusarium wilt and a concise set of race differentials for Fusarium oxysporum f. sp. ciceris. Plant Dis., 89(4): 385-395.

Simon, C.J. and Muehlbauer, F.J. 1997. Construction of a chickpea linkage map and its comparison with maps of pea and lentil. J. Hered., 88: 115-119.

Talebi, A. and KaramiE. 2011. Morphological and physiological traits associated with seed yield in different chickpea (Cicer arietinum L.) genotypes under irrigated and water-deficit environments. South Asia J. Exp. Biol., 1: 260-267.

Tanksley, S., N. Young, A. Paterson, Bonierbale, M. 1989. RFLP mapping in 
plant breeding: new tools for an old science. Biotech, 7: 257-264.

Tekeoglu, M., Rajesh, P.N. and Muehlbauer, F.J. 2002. Integration of sequence tagged microsatellite sites to the chickpea genetic map. Theor. Appl. Genet. 105: 847-854.

Toker, C. 2009. A note on the evolution of kabuli chickpeas as shown by induced mutations in Cicer reticulatum Ladizinsky. Genet. Resour. Crop Evol., 10.1007/s10722-008-9336-8.

Upadhyaya, H. D, Bramel, P. J, Singh, S. 2001. Development of a chickpea core subset using geographic distribution and quantitative traits. Crop Sci., 41: 206210.
Upadhyaya, H.D., Kumar, S. Gowda, C. Singh, S. 2006. Two major genes for seed size in chickpea (Cicer arietinum L.). Euphytica, 147: 311-315.

Winter, P., Benko-Iseppon, A. M., Huttel, B., Ratnaparkhe, M., Tullu, A., Sonnante, G., Pfaff, T., Tekeoglu, M., Santra, D. and Sant, V. 2000. A linkage map of the chickpea (Cicer arietinum L.) genome based on recombinant inbred lines from a $C$. arietinum $\times$ C. reticulatum cross: localization of resistance genes for Fusarium wilt races 4 and 5. Theor. Appl. Genet., 101(7): 1155-1167.

Zeng, Z. B. 1994. Precision mapping of quantitative trait loci. Genet., 136: 1457-1468.

\section{How to cite this article:}

Dalpat Lal and Ravikumar, R.L. 2018. Development of Genetic Linkage Map and Identification of QTLs for Agronomic Traits in Chickpea (Cicer arietinum L.). Int.J.Curr.Microbiol.App.Sci. 7(06): 66-77. doi: https://doi.org/10.20546/ijcmas.2018.706.010 